\title{
Colonoscopy quality in community hospitals and nonhospital facilities in Korea
}

\author{
Jae Gon Lee ${ }^{1}$, Dong Soo Han ${ }^{1}$, Young-Eun Joo², Dae-Seong Myung², Dong Il Park³, Seul Ki Kim³, \\ Yunho Jung, Won Hyun Lee ${ }^{4}$, Eun Soo Kim, Joon Seok Yoon ${ }^{5}$, and Chang Soo Eun ${ }^{1}$
}

\begin{abstract}
${ }^{1}$ Department of Internal Medicine, Hanyang University Guri Hospital, Guri; ${ }^{2}$ Department of Internal Medicine, Chonnam National University Medical School, Gwangju; ${ }^{3}$ Department of Internal Medicine, Kangbuk Samsung Hospital, Sungkyunkwan University School of Medicine, Seoul; ${ }^{4}$ Department of Internal Medicine, Soonchunhyang University College of Medicine, Cheonan; ${ }^{5}$ Department of Internal Medicine, Kyungpook National University Hospital, Daegu, Korea
\end{abstract}

\author{
Received: April 3, 2019 \\ Revised : June 12, 2019 \\ Accepted: December 23, 2019

\section{Correspondence to} \\ Dong Soo Han, M.D. \\ Department of Internal \\ Medicine, Hanyang University \\ Guri Hospital, 153 Gyeongchun- \\ ro, Guri 11923, Korea \\ Tel: +82-31-560-2226 \\ Fax: +82-31-555-2998 \\ E-mail: hands@hanyang.ac.kr \\ https://orcid.org/0000-0001- \\ 7103-3318
}

Background/Aims: High-quality colonoscopy is essential to reduce colorectal cancer-related deaths. Little is known about colonoscopy quality in non-academic practice settings. We aimed to evaluate the quality of colonoscopies performed in community hospitals and nonhospital facilities.

Methods: Colonoscopy data were collected from patients referred to six tertiary care centers after receiving colonoscopies at community hospitals and nonhospital facilities. Based on their photographs, we measured quality indicators including cecal intubation rate, withdrawal time, adequacy of bowel preparation, and number of polyps.

Results: Data from a total of 1,064 colonoscopies were analyzed. The overall cecal intubation rate was $93.1 \%$. The median withdrawal time was 8.3 minutes, but $31.3 \%$ of colonoscopies were withdrawn within 6 minutes. Community hospitals had longer withdrawal time and more polyps than nonhospital facilities (median withdrawal time: 9.9 minutes vs. 7.5 minutes, $p<0.001$; mean number of polyps: 3.1 vs. $2.3, p=0.001)$. Board-certified endoscopists had a higher rate of cecal intubation than non-board-certified endoscopists (93.2\% vs. $85.2 \%, p=0.006)$. A total of 819 follow-up colonoscopies were performed at referral centers with a median interval of 28 days. In total, 2,546 polyps were detected at baseline, and 1,088 were newly identified (polyp miss rate, 29.9\%). Multivariable analysis revealed that older age (odds ratio [OR], 1.032; 95\% confidence interval [CI], 1.020 to 1.044) and male sex (OR, 1.719; 95\% CI, 1.281 to 2.308) were associated with increased risk of missed polyps.

Conclusions: The quality of colonoscopies performed in community hospitals and nonhospital facilities was suboptimal. Systematic reporting, auditing, and feedback are needed for quality improvement.

Keywords: Colonoscopy; Quality improvement; Community hospital; Ambulatory care facilities

\section{INTRODUCTION}

Colorectal cancer (CRC) remains a major cause of cancer-related deaths worldwide [1]. CRC screening programs aim to reduce CRC-related mortality through early detection of cancer [2]. As most CRC develops gradually from adenomatous polyps through the adenoma-carcinoma sequence, it has been suggested that detection and removal of pre-cancerous lesions by colonoscopy can prevent development of CRC and reduce 
mortality associated with CRC $[3,4]$. Colonoscopy is the most sensitive tool for colorectal adenoma detection, and the detected adenoma can be resected during the procedure [5].

Although colonoscopy is regarded as the standard to detect and prevent CRC, this procedure has some limitations. Back-to-back colonoscopy revealed that the miss rate for adenomas of any size was $20 \%$ [6]. In addition, there are marked variations in polyp detection, complete polyp resection, and cancer prevention effects among fully trained colonoscopists [7-9]. Therefore, a high-quality colonoscopy is necessary to reduce CRC-related mortality. The American Society for Gastrointestinal Endoscopy guidelines provide quality indicators including cecal intubation rate $\geq 90 \%$, adequate bowel preparation $\geq 85 \%$, adenoma detection rate ( $\mathrm{ADR}$ ) $\geq 25 \%$, and average withdrawal time $\geq 6$ minutes to ensure adequate colonoscopy quality [10].

Colonoscopy is now widely used in various clinical practice settings not only in academic medical centers, but also in community hospitals and nonhospital facilities. In Korea, the National Endoscopy Quality Improvement Program exists for colonoscopy quality control [11]. However, little is known regarding the substantive quality of colonoscopy in real-life practice settings. It is important to maintain a similar level of colonoscopy quality among various clinical care settings in a population-based screening program. Therefore, we aimed to evaluate the quality of colonoscopies performed in community hospitals and nonhospital facilities in real-life practice.

\section{METHODS}

\section{Study population}

In six tertiary care centers participating in the study, patients who were referred with a copy of colonoscopy images from community hospitals and nonhospital facilities between January 1st, 2015 and December 31st, 2018 were retrospectively identified. Colonoscopy data were collected using the Picture Archiving and Communication System of each participating center. We excluded patients aged 19 or younger, those with colonic stricture or obstruction, inflammatory bowel disease, previous history of colectomy, unknown source of colonoscopy, and those without time records in the photographs. The study protocol was approved by the Institutional Review Board of each participating hospital (Hanyang University Guri Hospital IRB No. 2018-05-038). Informed consent was waived by the board because only de-identified data were collected retrospectively.

\section{Measurements and definition}

Based on photographs of the colonoscopies, we assessed quality indicators including cecal intubation rate, withdrawal time, adequacy of bowel preparation, rate of complete photo-documentation, and number of polyps. Cecal intubation was defined as the presence of a closeup photograph of the cecum with appendiceal orifice. Withdrawal time was measured as cecal intubation time minus finish time minus time spent on biopsy or polypectomy. The adequacy of bowel preparation was evaluated using the Boston Bowel Preparation Scale (BBPS) [12], and a total score $\geq 6$ was considered adequate bowel preparation. Complete photo-documentation was defined as the presence of the following representative landmark photographs: cecum, ileocecal valve, ascending colon, hepatic flexure, transverse colon, descending colon, sigmoid colon, and rectum.

Demographic data including age and sex were also collected. The practice setting in which each colonoscopy was performed was identified using the online hospital search provided by the Korean Ministry of Health and Welfare. Non-teaching medical institutions that do not provide inpatient care were classified as nonhospital facilities, and those that provide inpatient care were classified as community hospitals. Board certification of the endoscopist was assessed through an online search for board-certified endoscopists provided by the Korean Society of Gastrointestinal Endoscopy (KSGE). If a follow-up colonoscopy at the tertiary care center was performed, the number of newly detected polyps $\geq 5 \mathrm{~mm}$ in size was counted. The polyp miss rate was calculated as the total number of missed polyps / (total number of missed polyps + total number of polyps on initial examination) [13].

\section{Statistical analysis}

Continuous variables were expressed as mean \pm standard deviation or as median (interquartile range [IQR]) and compared using a $t$ test or Mann-Whitney test as appro- 
priate. Categorical variables were expressed as numbers (with proportion) and compared using the chi-square test with Fisher's exact test. Logistic regression models were used to evaluate risk factors for missed polyps. A $p$ value $<0.05$ was considered statistically significant. All statistical analyses were performed using $R$ statistical language R Studio version 3.4.3 (R Foundation for Statistical Computing, Vienna, Austria) and IBM SPSS Statistics version 20.0 (IBM Corp., Armonk, NY, USA).

\section{RESULTS}

\section{Baseline characteristics}

Data from a total of 1,184 colonoscopy procedures were collected; those of eight colonoscopies with colonic obstruction, 18 with inflammatory bowel disease, 58 with unknown source, and 36 without time records were excluded. Consequently, data from 1,064 colonoscopy procedures were analyzed. Of the colonoscopies, $57.8 \%$ were performed in nonhospital facilities and $42.2 \%$ in community hospitals. The median age of the patients was 59.0 years, and $62.5 \%$ were male. Of the endoscopists, $74.7 \%$ were board-certified. The reasons for referral were colorectal polyp (68.7\%), CRC (4.3\%), abdominal pain $(16.2 \%)$, subepithelial lesions of the gastrointestinal tract (5.3\%), and others (5.5\%) (Table 1 ).

\section{Measurement of quality indicators}

The overall cecal intubation rate was $93.1 \%$. The median withdrawal time was 8.3 minutes (IQR, 5.4 to 12.7), but colonoscopies with a withdrawal time $<6$ minutes accounted for $31.3 \%$. The percentage of colonoscopies with adequate bowel preparation (BBPS $\geq 6$ ) was $96.1 \%$. The mean number of photographs was 54.4, but complete photo-documentation was achieved in only $67.0 \%$ of exams. The presence of each landmark photograph was $93.1 \%$ in cecum, $78.1 \%$ in ileocecal valve, $95.7 \%$ in ascending colon, $89.3 \%$ in hepatic flexure, $96.7 \%$ in transverse colon, $95.9 \%$ in descending colon, $97.2 \%$ in sigmoid colon, and $96.1 \%$ in rectum. The mean number of polyps per exam was 2.6.

Comparing quality indicators according to practice setting, withdrawal time was significantly longer in community hospitals than in nonhospital facilities (median withdrawal time: 9.9 minutes vs. 7.5 minutes, $p<$
Table 1. Baseline characteristics $(n=1,064)$

\begin{tabular}{ll}
\hline Variable & \multicolumn{1}{c}{ Value } \\
\hline Age, yr & $59.0(50.0-68.0)$ \\
Sex & $665(62.5)$ \\
\hline \multicolumn{1}{l}{ Male } & $399(37.5)$ \\
\hline Female & \\
\hline Practice setting & $615(57.8)$ \\
\hline Nonhospital facility & $449(42.2)$ \\
\hline Community hospital & $108(10.2)$ \\
\hline Endoscopist certification & $795(74.7)$ \\
\hline Non-board-certified endoscopist & $161(15.1)$ \\
\hline Board-certified endoscopist & \\
\hline Unknown & $731(68.7)$ \\
\hline Reason for referral & $46(4 \cdot 3)$ \\
\hline Colorectal polyp & $172(16.2)$ \\
\hline Colorectal cancer & $56(5.3)$ \\
\hline Abdominal pain & $59(5.5)$ \\
\hline Subepithelial lesion & \\
\hline Others & \\
\hline
\end{tabular}

Values are presented as median (interquartile range) or number (\%).

${ }^{a}$ Others include upper gastrointestinal neoplasm and hepatobiliary diseases.

0.001; withdrawal time $\geq 6$ minutes: $74.2 \%$ vs. $64.7 \%, p=$ $0.001)$. The percentage of colonoscopies with complete photo-documentation was significantly higher in community hospitals than in nonhospital facilities $(73.9 \%$ vs. $62.0 \%, p<0.001$ ). More polyps were detected in colonoscopies at community hospitals than in those at nonhospital facilities (mean number of polyps: 3.1 vs. 2.3, $p=$ 0.001) (Table 2).

Using data from 903 colonoscopies performed by an identified board-certified endoscopist, we compared quality indicators according to board certification of the endoscopist. Board-certified endoscopists had a significantly higher rate of cecal intubation and larger number of photographs than non-board-certified endoscopists (cecal intubation rate: $93.2 \%$ vs. $85.2 \%, p=0.006$; mean number of photographs: 56.0 vs. $47.3, p=0.002$ ). Although board-certified endoscopists showed a higher rate of complete photo-documentation and a larger number of 
Table 2. Comparison of quality indicators according to practice setting

\begin{tabular}{|c|c|c|c|c|}
\hline \multirow[b]{2}{*}{ Variable } & \multicolumn{2}{|c|}{ Practice setting } & \multirow[b]{2}{*}{$p$ value } & \multirow[b]{2}{*}{$\begin{array}{c}\text { Total } \\
(\mathrm{n}=1,064)\end{array}$} \\
\hline & $\begin{array}{l}\text { Nonhospital facility } \\
\text { (n=615) }\end{array}$ & $\begin{array}{l}\text { Community hospital } \\
(\mathrm{n}=449)\end{array}$ & & \\
\hline Age, yr & $57.0(48.0-64.5)$ & $62.0(54.0-71.0)$ & $<0.001$ & $59.0(50.0-68.0)$ \\
\hline Male sex & $379(61.6)$ & $286(63.7)$ & 0.532 & $665(62.5)$ \\
\hline Cecal intubation rate, \% & 92.0 & 94.7 & 0.108 & 93.1 \\
\hline \multicolumn{5}{|l|}{ Withdrawal time } \\
\hline Median withdrawal time, min & $7 \cdot 5(5.2-11.0)$ & $9.9(5.8-15.2)$ & $<0.001$ & $8.3(5 \cdot 4-12.7)$ \\
\hline$\geq 6 \min$ & $398(64 \cdot 7)$ & $333(74.2)$ & 0.001 & $731(68.7)$ \\
\hline \multicolumn{5}{|l|}{ Bowel preparation } \\
\hline BBPS & $7 \cdot 9 \pm 1.2$ & $7.8 \pm 1.2$ & 0.258 & $7.8 \pm 1.2$ \\
\hline Adequate preparation & $589(95.8)$ & $434(96.7)$ & 0.561 & $1,023(96.1)$ \\
\hline Number of photographs & $55 \cdot 3 \pm 25 \cdot 4$ & $53.1 \pm 27.8$ & 0.194 & $54 \cdot 4 \pm 26.5$ \\
\hline Complete photo-documentation & $381(62.0)$ & $332(73.9)$ & $<0.001$ & $713(67.0)$ \\
\hline Number of polyps & $2.3 \pm 3.9$ & $3.1 \pm 3.0$ & 0.001 & $2.6 \pm 3.6$ \\
\hline
\end{tabular}

Values are presented as median (interquartile range), number (\%), or mean \pm SD.

BBPS, Boston Bowel Preparation Scale.

Table 3. Comparison of quality indicators according to endoscopist certification

\begin{tabular}{|c|c|c|c|}
\hline Variable & $\begin{array}{l}\text { Non-board-certified endoscopist } \\
\qquad(\mathrm{n}=108)\end{array}$ & $\begin{array}{l}\text { Board-certified endoscopist } \\
\qquad(\mathrm{n}=795)\end{array}$ & $p$ value \\
\hline Age, yr & $60.0(52.0-68.0)$ & $58.0(50.0-68.0)$ & 0.219 \\
\hline Male sex & $69(63.9)$ & $489(61.5)$ & 0.710 \\
\hline Cecal intubation rate, \% & 85.2 & 93.2 & 0.006 \\
\hline \multicolumn{4}{|l|}{ Withdrawal time } \\
\hline Median withdrawal time, min & $8.0(4.7-13.1)$ & $8.3(5 \cdot 5-12.6)$ & 0.409 \\
\hline$\geq 6 \min$ & $67(62.0)$ & $551(69 \cdot 3)$ & 0.157 \\
\hline \multicolumn{4}{|l|}{ Bowel preparation } \\
\hline BBPS & $7.8 \pm 1.2$ & $7 \cdot 9 \pm 1.2$ & 0.252 \\
\hline Adequate preparation & $103(95 \cdot 4)$ & $770(96.9)$ & 0.602 \\
\hline Number of photographs & $47 \cdot 3 \pm 25 \cdot 2$ & $56.0 \pm 27.0$ & 0.002 \\
\hline Complete photo-documentation & $63(58.3)$ & $533(67.0)$ & 0.092 \\
\hline Number of polyps & $2.2 \pm 2.3$ & $2.7 \pm 3.8$ & 0.052 \\
\hline
\end{tabular}

Values are presented as median (interquartile range), number (\%), or mean \pm SD.

BBPS, Boston Bowel Preparation Scale.

polyps than non-board-certified endoscopists, the differences were not statistically significant (Table 3).

In addition, colonoscopies with a withdrawal time $<6$ minutes had lower rates of cecal intubation and complete photo-documentation and fewer polyps per exam than colonoscopy with a withdrawal time $\geq 6$ minutes (cecal intubation rate: $88.6 \%$ vs. $95.2 \%, p<0.001$; complete photo-documentation rate: $54.1 \%$ vs. $72.9 \%, p$ $<0.001$; mean number of polyps: 1.8 vs. 3.0, $p<0.001$ ). 
Lee JG, et al. Colonoscopy quality in Korea

Table 4. Risk factors for missed polyp

\begin{tabular}{|c|c|c|c|c|}
\hline \multirow{2}{*}{ Variable } & \multicolumn{2}{|c|}{ Univariable analysis } & \multicolumn{2}{|c|}{ Multivariable analysis } \\
\hline & OR $(95 \% \mathrm{CI})$ & $p$ value & OR $(95 \% \mathrm{CI})$ & $p$ value \\
\hline Age & $1.032(1.020-1.044)$ & $<0.001$ & $1.032(1.020-1.044)$ & $<0.001$ \\
\hline \multicolumn{5}{|l|}{ Sex } \\
\hline Female & 1.000 & & 1.000 & \\
\hline Male & $1.712(1.283-2.283)$ & $<0.001$ & $1.719(1.281-2.308)$ & $<0.001$ \\
\hline \multicolumn{5}{|l|}{ Endoscopist certification } \\
\hline Board-certified endoscopist & 1.000 & & 1.000 & \\
\hline Non-board-certified endoscopist & $1.447(0.899-2.331)$ & 0.129 & $1.455(0.891-2.374)$ & 0.134 \\
\hline \multicolumn{5}{|l|}{ Practice setting } \\
\hline Community hospital & 1.000 & & 1.000 & \\
\hline Nonhospital facility & $0.802(0.607-1.060)$ & 0.121 & $0.929(0.681-1.267)$ & 0.642 \\
\hline \multicolumn{5}{|l|}{ Cecal intubation } \\
\hline Success & 1.000 & & 1.000 & \\
\hline Failure & $1.536(0.835-2.822)$ & 0.167 & $1.381(0.711-2.680)$ & 0.340 \\
\hline \multicolumn{5}{|l|}{ Withdrawal time } \\
\hline$\geq 6 \min$ & 1.000 & & 1.000 & \\
\hline$<6 \min$ & $0.860(0.629-1.175)$ & 0.343 & $0.988(0.701-1.393)$ & 0.946 \\
\hline \multicolumn{5}{|l|}{ Bowel preparation } \\
\hline Adequate & 1.000 & & 1.000 & \\
\hline Inadequate & $1.129(0.516-2.472)$ & 0.761 & $0.890(0.393-2.016)$ & 0.780 \\
\hline \multicolumn{5}{|l|}{ Photo-documentation } \\
\hline Complete & 1.000 & & 1.000 & \\
\hline Incomplete & $1.106(0.832-1.471)$ & 0.487 & $1.156(0.842-1.595)$ & 0.367 \\
\hline Number of polyps at baseline & $1.058(1.008-1.111)$ & 0.023 & $1.014(0.972-1.057)$ & 0.519 \\
\hline
\end{tabular}

The multivariable model included all variables and was selected by backward stepwise selection method.

OR, odds ratio; CI, confidence interval.

\section{Follow-up colonoscopy and missed polyps}

A total of 819 follow-up colonoscopies were performed at the tertiary care centers with a median interval of 28 days; 2,546 polyps were detected at baseline and 1,088 polyps were newly identified at follow-up colonoscopies (polyp miss rate, 29.9\%). Among newly detected polyps, 35 were histologically identified as adenocarcinoma.

Table 4 shows the univariable and multivariable logistic regression analyses for risk of missed polyps. Older age (adjusted odds ratio [OR], 1.032; 95\% confidence interval [CI], 1.020 to 1.044) and male sex (adjusted OR, 1.719; 95\% CI, 1.281 to 2.308 ) were significantly associated with an increased risk of missed polyps. The number of polyps at baseline was associated with missed polyps (unadjusted OR, 1.058; 95\% CI, 1.008 to 1.111), but the result was not significant on multivariable analysis (adjusted OR, 1.014; 95\% CI, 0.972 to 1.057).

\section{DISCUSSION}

In the present work, we found that the quality of colonoscopies performed in community hospitals and nonhospital facilities was suboptimal. Approximately one-third of colonoscopies were withdrawn within 6 minutes and had incomplete photo-documentation. Although the overall rate of cecal intubation exceeded $90 \%$, the cecal intubation rate of non-board-certified 
endoscopists was $85.2 \%$. Moreover, a large number of polyps were newly detected on follow-up exams within a short period of time.

According to previous studies conducted in Spain and the United States comparing the quality of colonoscopies between various practice settings, both academic and non-academic centers provided high-quality colonoscopies [14,15]. Our results, unlike previous studies, showed that the quality of colonoscopies in community hospitals and nonhospital facilities was suboptimal. In addition, community hospitals tend to perform colonoscopies of higher quality than nonhospital facilities. This disparity may be difficult to explain, given that there are numerous factors affecting the quality of care in medical practice environments [16]. In Korea, there is no medical budget for quality of care, and reimbursement for medical care is relatively low for nonhospital facilities. Indeed, the cost of a colonoscopy in Korea is approximately $\$ 72.6$ (1100.3 Korean won = 1 US dollar by an annual exchange rate in 2018) [17], which is significantly lower than the cost of approximately $\$ 899$ in the United States [18]. In addition, small-volume endoscopy units lack staff fully responsible for endoscopy and quality management. Meanwhile, it is also necessary to consider the possibility that excessive endoscopic workloads may result in suboptimal quality. Previous studies on the relationship between colonoscopy volume and quality have been inconclusive $[19,20]$. However, a recent study on the capacity for colonoscopies in Korea showed that there is a heavy colonoscopy workload and lack of capacity [21]. Further research and discussion on appropriate cost and colonoscopy workload is needed.

Interval CRCs, generally defined as CRCs after index colonoscopy before the next surveillance schedule, account for $1.8 \%$ to $9.0 \%$ of all CRCs [22]. Although the etiology of interval CRCs is unclear, the majority of interval CRCs originates from missed lesions [23]. Non-gastroenterologists and incomplete exams are associated with an increased risk of interval CRCs [24]. In our results, non-board-certified endoscopists had a higher rate of incomplete exams than board-certified endoscopists, although it was not an independent risk factor for missed polyps. It is worth noting that KSGE provides board certification to both internists and surgeons who have completed training at a designated training endoscopy center and have passed a qualifying examination [25].
In addition, to maintain qualifications, endoscopists should complete an annual education program including quality management [25]. This suggests that qualified endoscopists who were systematically trained in endoscopy and quality management are important for high-quality colonoscopies, regardless of their specialty in medical practice.

The suboptimal colonoscopy quality seen in community hospitals and nonhospital facilities in our results calls for strengthening quality management systems. In Korea, the National Cancer Screening Program (NCSP) provides fecal occult blood testing for adults 50 years of age or older and colonoscopies for positive cases [26]. For endoscopy quality management, NCSP operates an Endoscopy Quality Improvement Program, and revised quality indicators were recently published by the KSGE [11]. Quality indicators consist of 34 items in six areas of the workforce, process, facilities and equipment, outcome, reprocessing, and sedation [11]. However, endoscopy quality evaluation criteria only assess the overall quality of the institution, not the performance indicators of the individual endoscopist. Therefore, an individual endoscopist's cecal intubation rate, mean withdrawal time, and ADR are not measured. In addition, measurement of quality indicators depends on voluntary reporting by the endoscopist, and most end up with a document review without a field investigation. This suggests that current quality assessment and audit systems may be ineffective in real-life practice settings.

Poor-quality colonoscopies may cause not only interval CRCs and CRC-related deaths, but also overutilization, subsequent complications, and increased medical costs [27]. The cost for improving colonoscopy quality may be lower than the medical costs brought on by overutilization and subsequent complications associated with poor-quality colonoscopies. Cost-effective methods for quality improvement need to be discussed. In the United States, the Center for Medicare \& Medicaid Services has a Physician Quality Reporting System in which physicians voluntarily report endoscopy quality indicators and receive incentives [28]. In Spain, all screening colonoscopy data are coded by the coordinating staff in the Basque Country CRC Screening Program. In this way, data on colonoscopy quality indicators including ADR, cecal intubation rate, complications, and bowel preparation quality can be collected [14,29]. 
Ultimately, a comprehensive approach is needed to further improve the quality of colonoscopies in Korea. The first step is to refine the reporting system. According to a study conducted in Ontario, Canada, a considerable proportion of the colonoscopy reports submitted by the endoscopists in the field were inappropriate in quality [30]. Feedback is another important factor associated with quality improvement [31]. Providing appropriate feedback rather than auditing alone contributes to quality improvement, and providing incentives further increases effectiveness [31]. In addition, because it is not realistic to field investigate all institutions, an electronic database of colonoscopy quality indicators needs to be established. Pathological results after polypectomies should be collected to automatically calculate ADR and provide periodic feedback. Above all, to create a virtuous circle for quality improvement, it is important to encourage endoscopists to participate in the process of reporting, auditing, and providing feedback. To do so, the reporting system should be easy to implement, and appropriate feedback and incentives need to be provided.

This study has some limitations. Because colonoscopy data were retrospectively collected, we were not able to identify the indications for colonoscopy. Therefore, this study included colonoscopies of various indications besides screening colonoscopies. It may be inappropriate to directly apply our results to quality indicators of screening colonoscopies. Second, we measured withdrawal time as cecal intubation time minus finish time minus time spent on biopsy or polypectomy, which was an arbitrary measurement. In fact, withdrawal time $\geq 6$ minutes is a meaningful indicator in a negative study. Third, we were not able to investigate individual endoscopist ADR, which is an important indicator for endoscopist performance. The retrospective nature of the study limits the data collection; many colonoscopy pathologic reports were not available and a follow-up colonoscopy was not performed in all cases. Therefore, a complete assessment of adenoma detection could not be achieved. Fourth, bowel preparation was evaluated by the investigators, not by the operators. We used BBPS as a measure of bowel preparation, which relies on the degree of bowel visualization after sufficient washing and aspiration. Our method was limited in assessing bowel preparation accurately, because it was not possible to confirm that the pictures that the investigators used to evaluate bowel visualization were taken after sufficient washing and aspiration. Finally, we could not measure the level of experience of the endoscopist, nor the capacity and colonoscopy volume of each endoscopy unit. Future studies regarding colonoscopy quality indicators in non-academic centers including detailed information about endoscopists and endoscopy units are needed.

In conclusion, our results showed that the quality of colonoscopies performed in community hospitals and nonhospital facilities was suboptimal. Systematic reporting, auditing, and feedback are needed to establish a virtuous circle for colonoscopy quality improvement.

\section{KEY MESSAGE}

1. The quality of colonoscopies performed in community hospitals and nonhospital facilities in Korea was suboptimal. Several quality indicators did not meet the guideline recommendations, and a considerable number of polyps were missed.

2. Systematic reporting, auditing, and feedback are needed to improve the quality of colonoscopies.

\section{Conflict of interest}

No potential conflict of interest relevant to this article was reported.

\section{Acknowledgments}

This work was supported by the National Research Foundation of Korea (NRF) grant funded by the Korea government (MSIT) (2018R1A2B6004475).

\section{REFERENCES}

1. Torre LA, Bray F, Siegel RL, Ferlay J, Lortet-Tieulent J, Jemal A. Global cancer statistics, 2012. CA Cancer J Clin 2015;65:87-108.

2. Lauby-Secretan B, Vilahur N, Bianchini F, Guha N, Straif K; International Agency for Research on Cancer Handbook Working Group. The IARC perspective on colorectal cancer screening. N Engl J Med 2018;378:1734-1740.

3. Winawer SJ, Zauber AG, Ho MN, et al. Prevention of col- 
orectal cancer by colonoscopic polypectomy. The National Polyp Study Workgroup. N Engl J Med 1993;329:19771981.

4. Zauber AG, Winawer SJ, O'Brien MJ, et al. Colonoscopic polypectomy and long-term prevention of colorectal-cancer deaths. N Engl J Med 2012;366:687-696.

5. Dekker E, Rex DK. Advances in CRC prevention: screening and surveillance. Gastroenterology 2018;154:1970-1984.

6. Heresbach D, Barrioz T, Lapalus MG, et al. Miss rate for colorectal neoplastic polyps: a prospective multicenter study of back-to-back video colonoscopies. Endoscopy 2008;40:284-290.

7. Chen SC, Rex DK. Endoscopist can be more powerful than age and male gender in predicting adenoma detection at colonoscopy. Am J Gastroenterol 2007;102:856-861.

8. Pohl H, Srivastava A, Bensen SP, et al. Incomplete polyp resection during colonoscopy-results of the complete adenoma resection (CARE) study. Gastroenterology 2013;144:74-80.

9. Kaminski MF, Regula J, Kraszewska E, et al. Quality indicators for colonoscopy and the risk of interval cancer. N Engl J Med 2010;362:1795-1803.

10. Rex DK, Schoenfeld PS, Cohen J, et al. Quality indicators for colonoscopy. Gastrointest Endosc 2015;81:31-53.

11. Min JK, Cha JM, Cho YK, et al. Revision of quality indicators for the endoscopy quality improvement program of the National Cancer Screening Program in Korea. Clin Endosc 2018;51:239-252.

12. Lai EJ, Calderwood AH, Doros G, Fix OK, Jacobson BC. The Boston bowel preparation scale: a valid and reliable instrument for colonoscopy-oriented research. Gastrointest Endosc 2009;69(3 Pt 2):620-625.

13. Ahn SB, Han DS, Bae JH, Byun TJ, Kim JP, Eun CS. The miss rate for colorectal adenoma determined by quality-adjusted, back-to-back colonoscopies. Gut Liver 2012;6:64-70.

14. Portillo I, Idigoras I, Bilbao I, et al. Colorectal cancer screening program using FIT: quality of colonoscopy varies according to hospital type. Endosc Int Open 2018;6:E1149-E1156.

15. Inra JA, Nayor J, Rosenblatt M, et al. Comparison of colonoscopy quality measures across various practice settings and the impact of performance scorecards. Dig Dis Sci 2017;62:894-902.

16. Hanefeld J, Powell-Jackson T, Balabanova D. Understanding and measuring quality of care: dealing with complex- ity. Bull World Health Organ 2017;95:368-374.

17. National Health Insurance Service. Insurance benefit costs [Internet]. Wonju (KR): National Health Insurance Service, c2011 [cited 2020 Apr 29]. Available from: https:// www.nhis.or.kr/menu/retriveMenuSet.xx?menuId=F3254.

18. Meester RG, Doubeni CA, Lansdorp-Vogelaar I, et al. Variation in adenoma detection rate and the lifetime benefits and cost of colorectal cancer screening: a microsimulation model. JAMA 2015;313:2349-2358.

19. Adler A, Wegscheider K, Lieberman D, et al. Factors determining the quality of screening colonoscopy: a prospective study on adenoma detection rates, from 12,134 examinations (Berlin colonoscopy project 3, BECOP-3). Gut 2013;62:236-241.

20. Pace D, Borgaonkar M, Lougheed M, et al. Effect of colonoscopy volume on quality indicators. Can J Gastroenterol Hepatol 2016;2016:2580894.

21. Choi JH, Cha JM, Yoon JY, Kwak MS, Jeon JW, Shin HP. The current capacity and quality of colonoscopy in Korea. Intest Res 2019;17:119-126.

22. Singh S, Singh PP, Murad MH, Singh H, Samadder NJ. Prevalence, risk factors, and outcomes of interval colorectal cancers: a systematic review and meta-analysis. Am J Gastroenterol 2014;109:1375-1389.

23. le Clercq CM, Bouwens MW, Rondagh EJ, et al. Postcolonoscopy colorectal cancers are preventable: a population-based study. Gut 2014;63:957-963.

24. Baxter NN, Sutradhar R, Forbes SS, Paszat LF, Saskin R, Rabeneck L. Analysis of administrative data finds endoscopist quality measures associated with postcolonoscopy colorectal cancer. Gastroenterology 2011;140:65-72.

25. Moon HS, Choi EK, Seo JH, et al. Education and training guidelines for the Board of the Korean Society of Gastrointestinal Endoscopy. Clin Endosc 2017;50:345-356.

26. Yoo KY. Cancer control activities in the Republic of Korea. Jpn J Clin Oncol 20o8;38:327-333.

27. Paszat L, Sutradhar R, Baxter NN, Tinmouth J, Rabeneck L. Repeat colonoscopy within 6 months after initial outpatient colonoscopy in Ontario: a population-based cross-sectional study. Can J Gastroenterol Hepatol 2017;2017:5917057.

28. Dowd B, Li CH, Swenson T, Coulam R, Levy J. Medicare's Physician Quality Reporting System (PQRS): quality measurement and beneficiary attribution. Medicare Medicaid Res Rev 2014;4. http://dx.doi.org/10.5600/mmrr.004.02. ao4.

29. Idigoras I, Arrospide A, Portillo I, et al. Evaluation of the 
colorectal cancer screening Programme in the Basque Country (Spain) and its effectiveness based on the Miscan-colon model. BMC Public Health 2017;18:78.

30. Hadlock SD, Liu N, Bernstein M, et al. The quality of colonoscopy reporting in usual practice: are endoscopists reporting key data elements? Can J Gastroenterol Hepa- tol 2016;2016:1929361.

31. Webster F, Patel J, Rice K, et al. How to make feedback more effective? Qualitative findings from pilot testing of an audit and feedback report for endoscopists. Can J Gastroenterol Hepatol 2016;2016:4983790. 